\title{
The representativity index of a simple monitoring network with regular theoretical shapes and its practical application for the existing groundwater monitoring network of the Tychy-Urbanowice landfills, Poland
}

\author{
Dominika Dąbrowska $^{1}$ Rafał Kucharski ${ }^{2}$ Andrzej J. Witkowski ${ }^{1}$
}

Received: 29 October 2015/Accepted: 9 March 2016/Published online: 25 April 2016

(c) The Author(s) 2016. This article is published with open access at Springerlink.com

\begin{abstract}
The representativity index $R_{\mathrm{u}}$ is a measure used in assessing the chemical status of groundwater based on monitoring studies. This index is designed to describe the spatial homogeneity of the monitoring network. The general formula for calculating the index $R_{\mathrm{u}}$ includes the following parameters: average distance to the nearest monitoring point, number of monitoring points, and size of the test area. Calculations to determine the representativity index for four different shapes of the theoretical test study with the same area and the same number of monitoring points have been done. These calculations suggest that the index value depends on the shape and the position of these points, and it is less dependent on the size of the surface. An assessment of the representativeness of the monitoring network for the different numbers and configurations of the piezometers around the Tychy-Urbanowice landfills based on the mentioned index has been done as well. The best and the worst configurations of the monitoring network for these landfill sites in mathematical terms have been presented in this paper. The results are surprising: the highest index value is obtained with a single measurement point. The calculations were performed with the area of landfill and the area limited by the range of piezometers as the exclusive test area. To choose the optimal test area, representativity indicator was calculated also for the monitoring network around waste
\end{abstract}

Dominika Dąbrowska

dominika.dabrowska1989@gmail.com;

ddabrowska@us.edu.pl

1 Department of Hydrogeology and Engineering Geology, University of Silesia, Będzińska 60, 41-200 Sosnowiec, Poland

2 Department of Statistics, University of Economics, 1 Maja 50, 40-287 Katowice, Poland landfills, including the buffer network behind the piezometers. The difference in the values of the representativity indicator for subsequent variants is astounding. The representativity index for the same monitoring network is about $20 \%$ higher if we consider the test area limited by external piezometers, and higher by another $20 \%$, taking into account the $95-\mathrm{m}$ buffer zone behind piezometers. Due to increase of the representativity index value with a different width of buffer zone, the mathematical calculations of the monitoring network's representativeness should be supported by an analysis of the geological structure and hydrogeological conditions occurring in the analyzed area.

Keywords Representativity index · Monitoring network · Chemical state of groundwater - Mathematical model

\section{Introduction}

The monitoring and representativeness of a sampling of groundwater is a difficult and complex process resulting from the substantial spatial variability of the groundwater composition, limited access to the aquifer and quite frequently, a conceptually inadequate model of the monitoring system with poorly defined recharge and discharge zones.

It has to be mentioned that even in quite simple conditions with a limited spatial variability of groundwater composition, the reliability of three downgradient piezometers can be not appropriate from the point of view of groundwater pollution risk assessment (Witczak et al. 2006).

The monitoring network design depends on the objectives of the monitoring. The basic objective of groundwater quality monitoring is the detection and evaluation of changes in groundwater quality. According to the Water Framework Directive (WFD) of the EU, monitoring should 
control the input of pollutants into the groundwater locally (point sources), and control the status of all groundwater bodies. In both cases, proper monitoring network design should include the same factors (e.g. geology, hydrogeology, recharge and discharge zones, the migration time of contaminants, land use and human impact, regulatory requirements) but could be different in some details, e.g.: the number and location of observation wells, their construction, the sampling frequency and the range of measurements taken according to environmental standards (Witczak et al. 2006). Different approaches have been proposed to establish a representative monitoring network for the abovementioned both cases, but up to now there is no generally accepted methodology (Nielsen 2006; Jousma and Roelofsen 2004; Grath et al. 2001; Quevauviller et al. 2009). For instance, a minimum number of three sampling points in groundwater monitoring network per groundwater body or potential pollution source (Grath et al. 2001; Witkowski 2009) is required.

\section{Methodology}

Grath et al. (2001) argued that the monitoring network, to enable a good estimate of the chemical status of groundwater, should be homogeneous, and proposed the following representativity index $R_{\mathrm{u}}$, as a measure to evaluate this property by mathematical methods. The index is calculated by the formula:

$R_{\mathrm{u}}=\frac{37.7}{d_{\mathrm{av}} \sqrt{\frac{n}{F}}}(\%)$

where: $d_{\mathrm{av}}$-average distance to the nearest monitoring point (m), $n$-number of monitoring points, $F$-size of the test area $\left(\mathrm{m}^{2}\right)$.

The idea of this index is quite clear: for homogenous network, locations of monitoring points should be chosen in such a way, that the distance from any point in the area to the nearest monitoring point is small, relatively to the area of the test site. Thus, the higher the ratio, the more homogenous the monitoring network is. The role of the constant in the nominator is to normalize values of index to interval from 0 to $100 \%$, citing Grath et al. (2001): "For a theoretical network with an optimal triangular pattern of sites the Representativity Index will be $100 \%$. For suboptimal (less homogeneous) networks the index will decrease". However, for a theoretical example of circular area with single monitoring point in the center, we obtain value of representativity index slightly exceeding $100 \%$ (Dabrowska et al. 2013). Moreover, it is recognized that the monitoring network is representative, if $R_{\mathrm{u}} \geq 80 \%$ (Rentier et al. 2006).
Substantial difficulty in calculating representativity index is the necessity of determining the value $d_{\mathrm{av}}$-average distance to the nearest monitoring point. In practice, computations are done (by computer) with the following steps:

1. Test area is replaced by a discrete grid of points.

2. For every point from the grid, distances to measurement points are calculated, and the lowest distance is chosen (distance to the nearest measurement point).

3. Value of $d_{\mathrm{av}}$ is calculated as a simple arithmetic mean of those lowest distances.

Although there exists the software tool Gwstat (downloadable from http://www.wfdgw.net), that allows the calculation of representativity index, for our purposes we have wrote and used the script in R programming language (R Core Team 2015).

To illustrate the behavior of the representativity index, at first we studied the relationship between different shapes of the area and the value of index. The following shapes were selected (arbitrarily): a triangle, a square (two times) and a deltoid-like shape with square-shaped hole. To ease the comparison of results, their sizes have been set such that areas of all shapes are equal. On these shapes, we put the same configuration of three points to function as a monitoring network. Shapes with configurations of monitoring points are presented on Fig. 1.

The results of the representativity index $\left(R_{\mathrm{u}}\right)$ and the mean minimum distance between any point in a given area and the nearest point of measurement $\left(d_{\mathrm{av}}\right)$ calculation are presented in Table 1.

As we can see, the representativity index depends both on the shape of the study area as well as on the positions of the piezometers within the monitored area. The size of the area itself is not important. The most interesting aspect is the comparison of two squares (Fig. 1b, c). When the monitoring points are located in the central part of the area, the index is higher more than 25 percentage points. In addition, in this case only the value of representativity index is greater than recommended $80 \%$. Non-central location of monitoring points (Fig. 1c) or irregular shape (Fig. 1d) results in values below $60 \%$. These examples also show how hard it is to obtain monitoring network meeting the representativity criteria $\left(R_{\mathrm{u}} \geq 80 \%\right)$ for a given area shape, in an intuitive (or naïve) manner.

\section{Applications}

In this paper, we tested the possibility of practical use of that index to assess the representativeness of the groundwater monitoring local network of landfills. 
Fig. 1 Shapes of the theoretical study areas
A

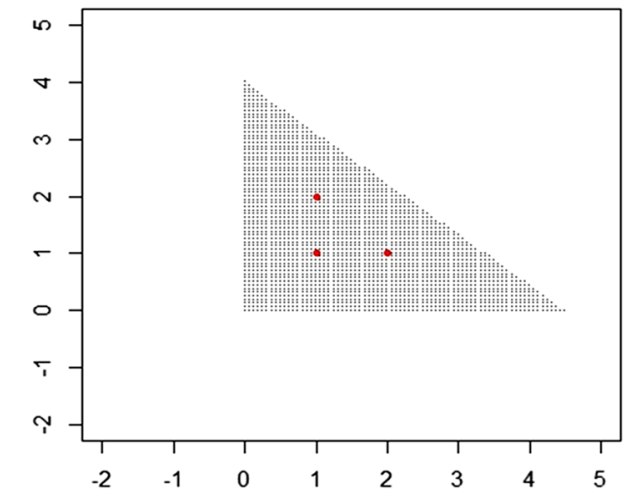

C

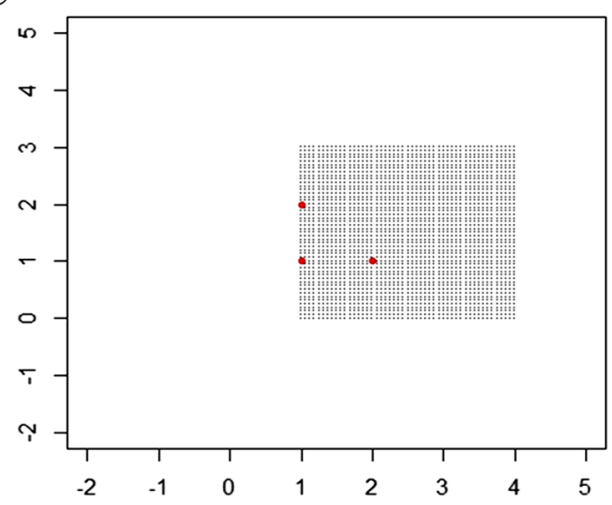

B

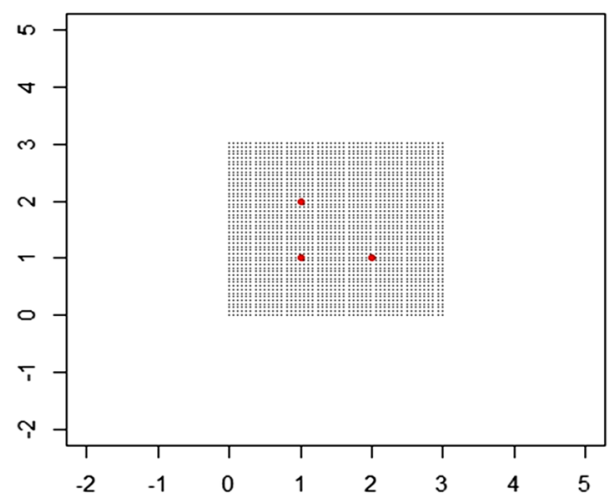

D

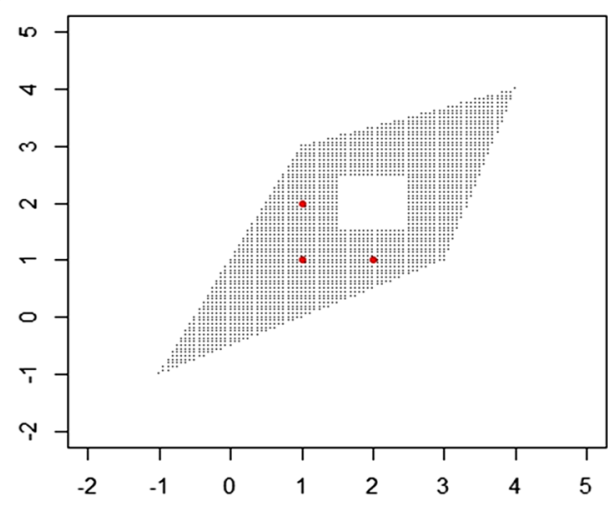

Table 1 Results for the considered shapes of the theoretical study areas

\begin{tabular}{lll}
\hline Option & $R_{\mathrm{u}}(\%)$ & $d_{\mathrm{av}}(\mathrm{m})$ \\
\hline A. Triangle & 79.54 & 0.83 \\
B. Square 1 & 83.68 & 0.79 \\
C. Square 2 & 57.95 & 1.15 \\
D. Deltoid & 57.44 & 1.15 \\
\hline
\end{tabular}

\section{Study area}

System of landfills in Tychy-Urbanowice was selected as an area of research. It is located at the confluence of two surface streams - the Tychy Stream and the Gostynia River in the southern part of Poland. There are two landfills: an active one and an abandoned one (Fig. 2). The old unsealed site had been working since before 1988 as a building materials landfill and later, as a sanitary landfill. This part has been closed in 1994. The new active part covers more than $70,000 \mathrm{~m}^{2}$ and consists of two sealed landfills.

The study area is situated in the central part of the Upper Silesian Coal Basin, within the Carpathian Foredeep. There are Carboniferous, locally Triassic, Neogene (Miocene) and Quaternary sediments in the geological profile of the research area. The most important are the Quaternary sediments with the thickness in the range between 12.5 and $17 \mathrm{~m}$. There are Pleistocene river and hollow accumulation sediments (sands, gravels, locally silty clays). The thickness of the loamy interbedding is equal to about 1-3 m (Witkowski 2006).

There are quite simple hydrogeological conditions in the research area. The hydrogeological profile of the study area is represented by three multiaquifer formations-Quaternary, Triassic and Carboniferous. The most important is a shallow Quaternary sand and gravel aquifer that has been subjected to the negative impact of the old unsealed landfill. Multiaquifer formations located underneath the Quaternary are covered by thick Tertiary clays and are not threatened by the anthropogenic influence. The groundwater flow within the Quaternary aquifer occurs from the north to the south.

Groundwater monitoring of the Quaternary aquifer has worked in this area since 1995. The original network was made at the end of 1993 and the beginning of 1994, and consisted of 14 piezometers (P1, P2, P3, P4, P5, P6, P7, P8, P9, P10, P11, P12, P13, P14) which monitored the old landfill (I) and the new active part (II) (Fig. 2). Before the extension of the active landfill to the second new part (III), 3 piezometers were liquidated (P5, P6, P7) and 3 new were drilled (P5', P15, P16). In 2007-2008, five new piezometers were drilled (P17, P17A, P18, P19, P19A) and up until 2010, the groundwater monitoring network consisted of 19 observation wells (Fig. 2). Finally, as a result of progressive reorganizations, the monitoring network has been divided into two subsystems, which currently involves 15 


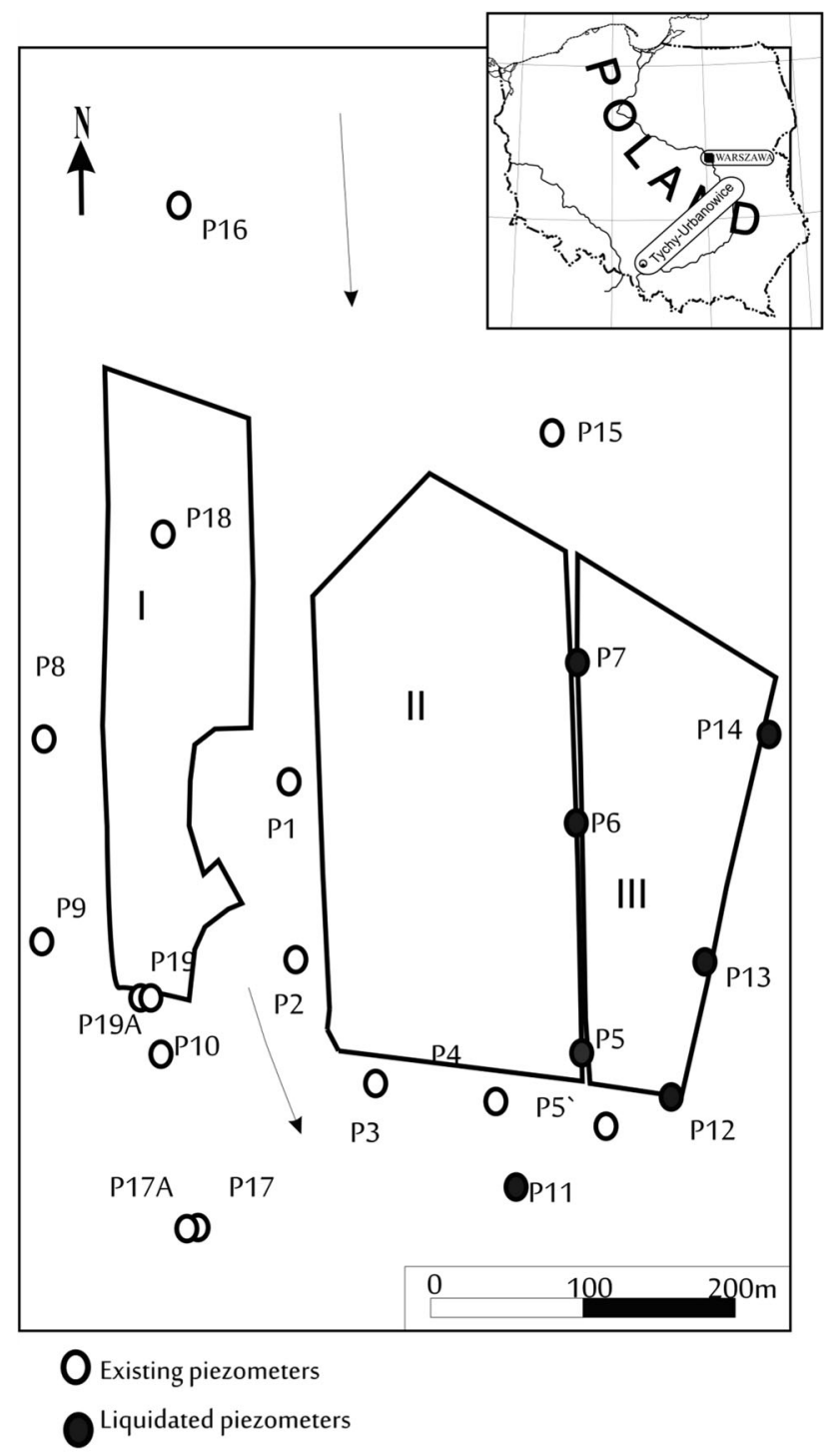

I Inactive landfill

II, III Active landfill

\section{$\swarrow$ Groundwater flow direction}

Fig. 2 The system of landfills in Tychy-Urbanowice

piezometers, including two pairs of nested piezometers (P17, P17A and P19, P19A) (Fig. 2). The first subsystem, monitoring area of the inactive landfill, comprises of 11 piezometers-P1, P2, P8, P9, P10, P16, P17, P17A, P18, $\mathrm{P} 19, \mathrm{P} 19 \mathrm{~A}$. Piezometer P18 is particularly important, as it is located on the top of the inactive site. The second subsystem is implemented under the local groundwater quality monitoring of active landfills, and consists of only seven piezometers-P1, P2, P3, P4, P5', P15, P16 (Dąbrowska 2012).

The existing monitoring network was analyzed in terms of its theoretical representativeness considering the effect of the adopted shape of the research area and the number of observation points on the representativity index's values.

Piezometers within the two nests (P17, P17A and P19, P19A) that are located very close to each other, for the purpose of calculations were treated respectively as two single points (P17 and P19). First, calculations were done for the system of landfills treated as one area (Fig. 3a). Later on, the old landfill (Fig. 3b) and the new landfill (Fig. 3c) were treated as separate areas. In this setting, representativity index has been calculated for every subset of the set of 17 existing piezometers, resulting in 131,071 index values for each of three considered areas.

The calculated index value varies from $21.83 \%$ (for the set of 9 piezometers: $\mathrm{P} 3, \mathrm{P} 4, \mathrm{P} 5{ }^{\prime}, \mathrm{P} 9, \mathrm{P} 10, \mathrm{P} 11, \mathrm{P} 12, \mathrm{P} 17$, P19) to $75.61 \%$ (for single piezometer: P1). The values of $R_{\mathrm{u}}$ for the case where the system of landfills was treated as one area (Fig. 3a) are presented graphically in Fig. 4.

The points in the bottom line correspond to sets of single piezometers, while the point at the top shows the representativity index calculated for all existing piezometers. As we can see, results obtained for the entire area do not indicate any clear relationship between the number of piezometers and the value of the index $R_{\mathrm{u}}$. Table 2 presents the biggest index value for a given number of piezometers in the monitoring network, and the set of piezometers for which this value was obtained. The highest index value for the whole area is reached not for the set of all piezometers but just for the single piezometer, namely-P1. Moreover, and what is surprising, representativity index seems to decrease for increasing number of piezometers.

To understand thoroughly these results, relationship between the set of piezometers chosen for calculations and the average distance to the nearest piezometer was also investigated. The average distance to the nearest piezometers range between 83.3 and $398.8 \mathrm{~m}$. Results are presented graphically in Fig. 5 .

As we can see, in this particular case of existing monitoring network of piezometers, values of the average distance to the nearest monitoring point can be close to minimal $(83.5 \mathrm{~m})$ for the subsets consisting of just seven piezometers. Moreover, additional piezometers have no impact on further decrease of this number. Points in the bottom line correspond to single piezometers, and for the $\mathrm{P} 1$ piezometer, the average distance to the points of study area is equal to $170.45 \mathrm{~m}$, only twice more than the minimal, resulting in maximal value of representativity index. Of course, the reason for such a behavior may lay in improper (from the point of view of representativity index) location of piezometers, however, we think that it is rather an internal feature of the representativity index.

In accordance with Polish regulations, the monitoring network should consist at least of one upgradient and two downgradient observation wells. Example of such a 


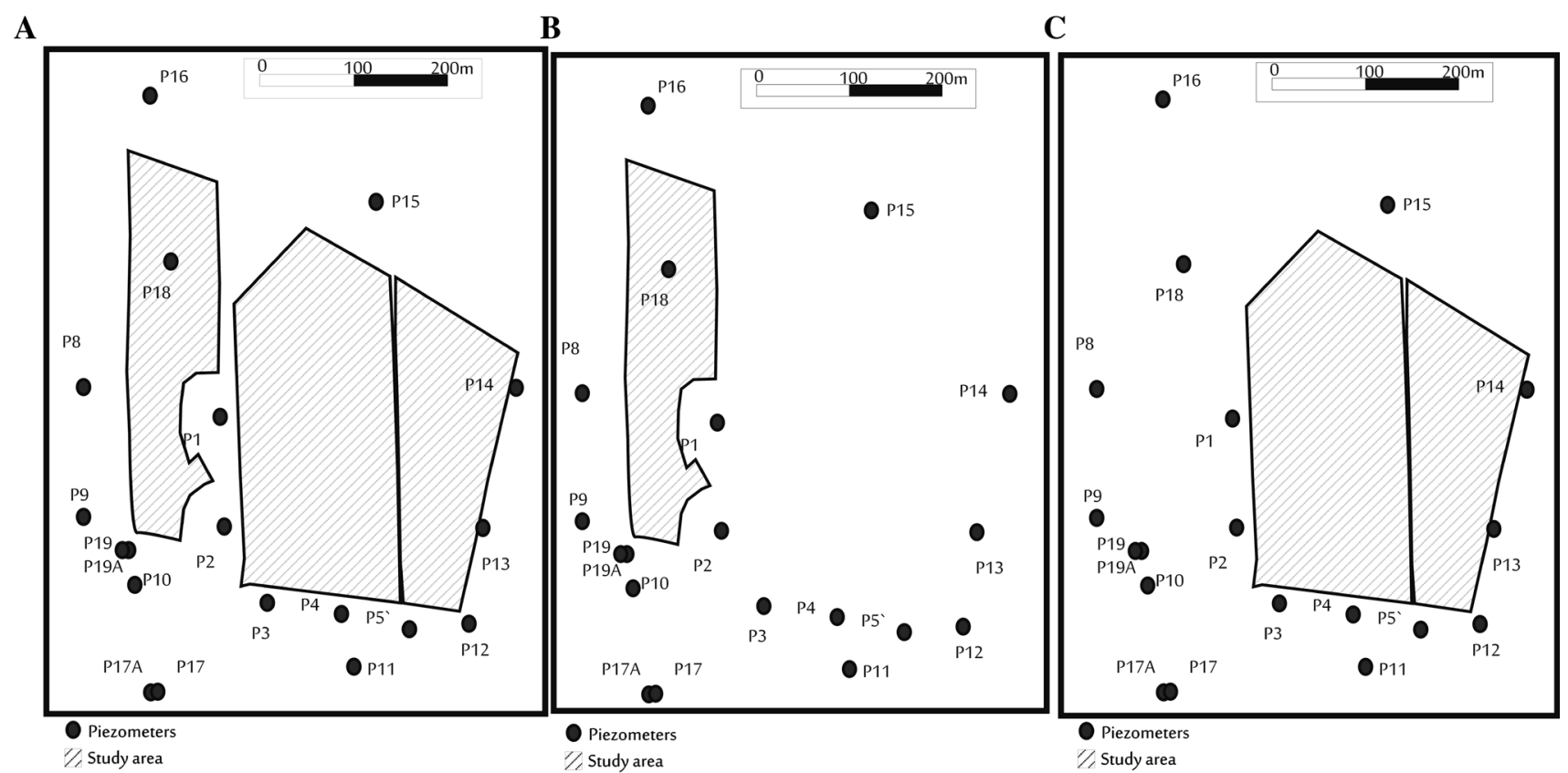

Fig. 3 The shapes of the study areas and piezometers networks: a entire area including both the old and active landfills, b old landfill, $\mathbf{c}$ active landfill

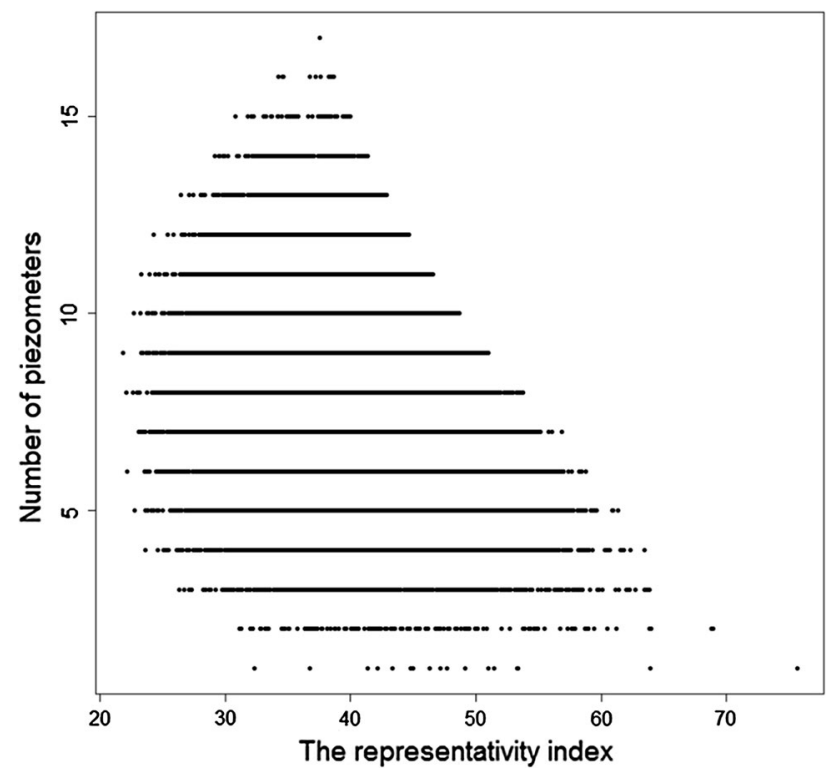

Fig. 4 Representativity index $\left(R_{\mathrm{u}}\right)$ value for different subsets of piezometers

network consists of P16 (inflow), P4 and P10 (outflow), for which representativity index is equal to $38.60 \%$. Another, larger example of network, which seems to be good from the point of view of hydrogeological research is as follows: $\mathrm{P} 15$ for the active site, P16 for the old one in the inflow, P3, $\mathrm{P}^{\prime}$ for the active site, P10, P19 for the old one in the outflow, however, for these 6 piezometers, $R_{\mathrm{u}}=34.03 \%$. Values of representativity index obtained for these two example networks are very low in comparison to overall maximal value $75.61 \%$, as well as to values 65.00 and $58.21 \%$, that can be obtained for networks consisting respectively of 3 and 6 piezometers.

Similar calculations have been made separately for the areas of the old landfill and the new one. Maximal values of representativity index have been obtained for the sets consisting of piezometers:

- $\quad$ P2, P18 for the old landfill, $R_{\mathrm{u}}=69.46 \%$,

- $\quad$ P14 for the new landfill, $R_{\mathrm{u}}=56.60 \%$.

Again, higher representativity index values are obtained for small number of piezometers. When some piezometer is located sufficiently far from the landfill, its addition to given network does not decrease average distance to the nearest measurement point, but increases the number of piezometers, thus lowering the value of representativity index. This way, the minimal values of $\mathrm{d}_{\mathrm{av}}$ have been obtained for the sets:

- $\quad \mathrm{P} 1, \mathrm{P} 2, \mathrm{P} 8, \mathrm{P} 9, \mathrm{P} 10, \mathrm{P} 16, \mathrm{P} 17, \mathrm{P} 18, \mathrm{P} 19$ for the old site, $R_{\mathrm{u}}=39.57 \%$,

- P1, P2, P3, P4, P5', P11, P12, P13, P14, P15 for the new site, $R_{\mathrm{u}}=35.89 \%$.

Example networks consisting of a minimum number of three piezometers give us $24.91 \%$ (P10, P16, P19) for old landfill and $41.23 \%\left(\mathrm{P} 3, \mathrm{P}^{\prime}, \mathrm{P} 15\right)$ for active landfill. These results are summarized in Tables 3 and 4 . 
Table 2 The maximum value of representativity index for different number of points and the best piezometers set for a given configuration (from 1 to 17 piezometers)

\begin{tabular}{|c|c|}
\hline Number of points and piezometer sets & $R_{\mathrm{u}} \max (\%)$ \\
\hline $1-\mathrm{P} 1$ & 75.61 \\
\hline 2-P1, P13 & 68.92 \\
\hline $3-\mathrm{P} 2, \mathrm{P} 14, \mathrm{P} 18$ & 65.00 \\
\hline 4-P1, P4, P14, P18 & 62.99 \\
\hline 5-P1, P2, P13, P14, P18 & 60.87 \\
\hline $6-\mathrm{P} 1, \mathrm{P} 2, \mathrm{P} 13, \mathrm{P} 14, \mathrm{P} 15, \mathrm{P} 18$ & 58.21 \\
\hline 7-P1, P2, P4, P13, P14, P15, P18 & 56.32 \\
\hline 8 -P1, P2, P4, P13, P14, P15, P18, P19 & 53.23 \\
\hline 9—P1, P2, P3, P4, P13, P14, P15, P18, P19 & 50.49 \\
\hline $10-\mathrm{P} 1, \mathrm{P} 2, \mathrm{P} 3, \mathrm{P} 4, \mathrm{P}^{\prime}, \mathrm{P} 13, \mathrm{P} 14, \mathrm{P} 15, \mathrm{P} 18, \mathrm{P} 19$ & 48.17 \\
\hline 11-P1, P2, P3, P4, P5', P8, P13, P14, P15, P18, P19 & 46.03 \\
\hline 12—P1, P2, P3, P4, P5, P8, P9, P13, P14, P15, P18, P19 & 44.15 \\
\hline 13-P1, P2, P3, P4, P5', P8, P9, P10, P13, P14, P15, P18, P19 & 42.49 \\
\hline 14-P1, P2, P3, P4, P5', P8, P9, P10, P12, P13, P14, P15, P18, P19 & 40.97 \\
\hline 15-P1, P2, P3, P4, P5', P8, P9, P10, P12, P13, P14, P15, P16, P18, P19 & 39.59 \\
\hline 16-P1, P2, P3, P4, P5', P8, P9, P10, P11, P12, P13, P14, P15, P16, P18, P19 & 38.33 \\
\hline 17-P1, P2, P3, P4, P5', P8, P9, P10, P11, P12, P13, P14, P15, P16, P17, P18, P19 & 37.19 \\
\hline
\end{tabular}

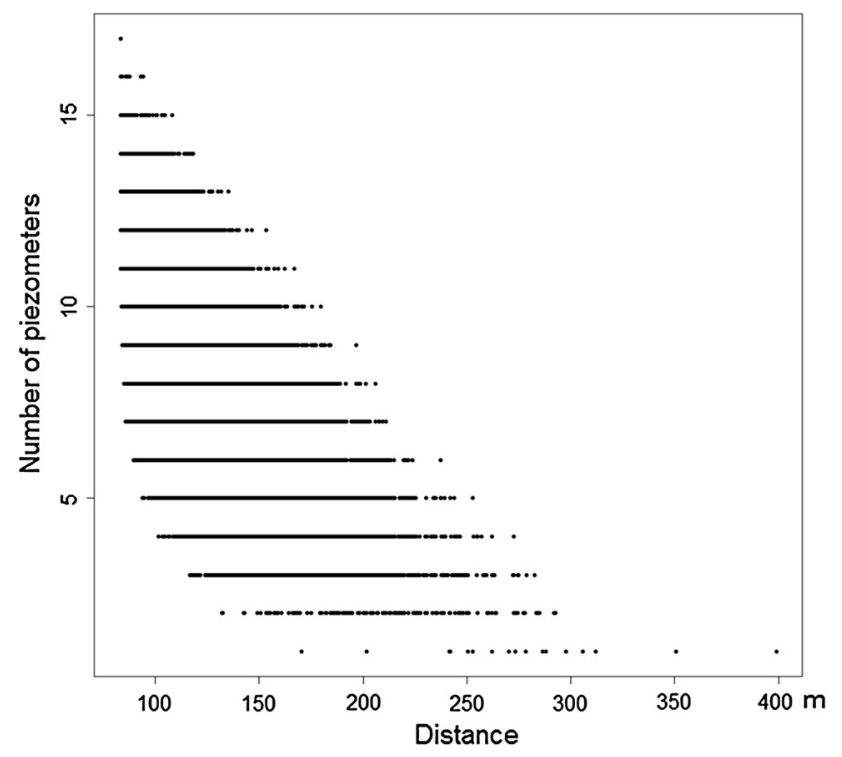

Fig. 5 Average distance to the nearest measurement point $\left(d_{\text {av }}\right)$ for different subsets of piezometers

The results of calculations of the representativity index $\left(R_{\mathrm{u}}\right)$ presented above, performed for the test areas including exclusively the area of landfills demonstrate in general low values of the index, not exceeding $80 \%$. In this context, it was decided that test areas will be modified (extended) and the influence of such changes on the obtained values of the $R_{\mathrm{u}}$ index determined. This attitude aimed at choosing the variant with an optimal test area and optimal number of monitoring points located within it, for which maximal values of the $R_{\mathrm{u}}$ index were obtained (exceeding the
Table 3 Values of $R_{u}$ index for the old landfill site (Fig. 3b)

\begin{tabular}{lll}
\hline No. & Piezometers sets & $R_{\mathrm{u}}(\%)$ \\
\hline 1 & P2, P18 & 69.46 \\
2 & P10, P16, P19 & 24.91 \\
3 & P1, P2, P8, P9, P10, P16, P17, P18, P19 & 39.57 \\
\hline
\end{tabular}

Table 4 Values of $R_{\mathrm{u}}$ index for the new landfill site (Fig. 3c)

\begin{tabular}{lll}
\hline No. & Piezometers sets & $R_{\mathrm{u}}(\%)$ \\
\hline 1 & $\mathrm{P} 14$ & 56.60 \\
2 & $\mathrm{P} 3, \mathrm{P} 5^{\prime}, \mathrm{P} 15$ & 41.23 \\
3 & $\mathrm{P} 1, \mathrm{P} 2, \mathrm{P} 3, \mathrm{P} 4, \mathrm{P}^{\prime}, \mathrm{P} 11, \mathrm{P} 12, \mathrm{P} 13, \mathrm{P} 14, \mathrm{P} 15$ & 35.89 \\
\hline
\end{tabular}

suggested $80 \%$ ). The calculations were performed for three areas with landfills and surrounding piezometers, i.e. for both landfills (Fig. 6a) $F=292,621 \mathrm{~m}^{2}$, for the old landfill (Fig. 6b), $F=154,656 \mathrm{~m}^{2}$ and for the new landfill $F=188,916 \mathrm{~m}^{2}$.

Optionally, the entire monitoring network was taken into account in the calculations for each of the three areas, together with the network optimal from the hydrogeological point of view as well as the minimal network (consistent with the regulations in force). Results of the $R_{\mathrm{u}}$ factor obtained for subsequent options are relatively high, and fall between 50 and $70 \%$, however not exceeding $80 \%$ (Tables 5, 6, 7). For example, high value of this factor reaching $70 \%$ was obtained for the variant including all 17 piezometers and this number may be considered optimal from the point of view of the analyzed index. 


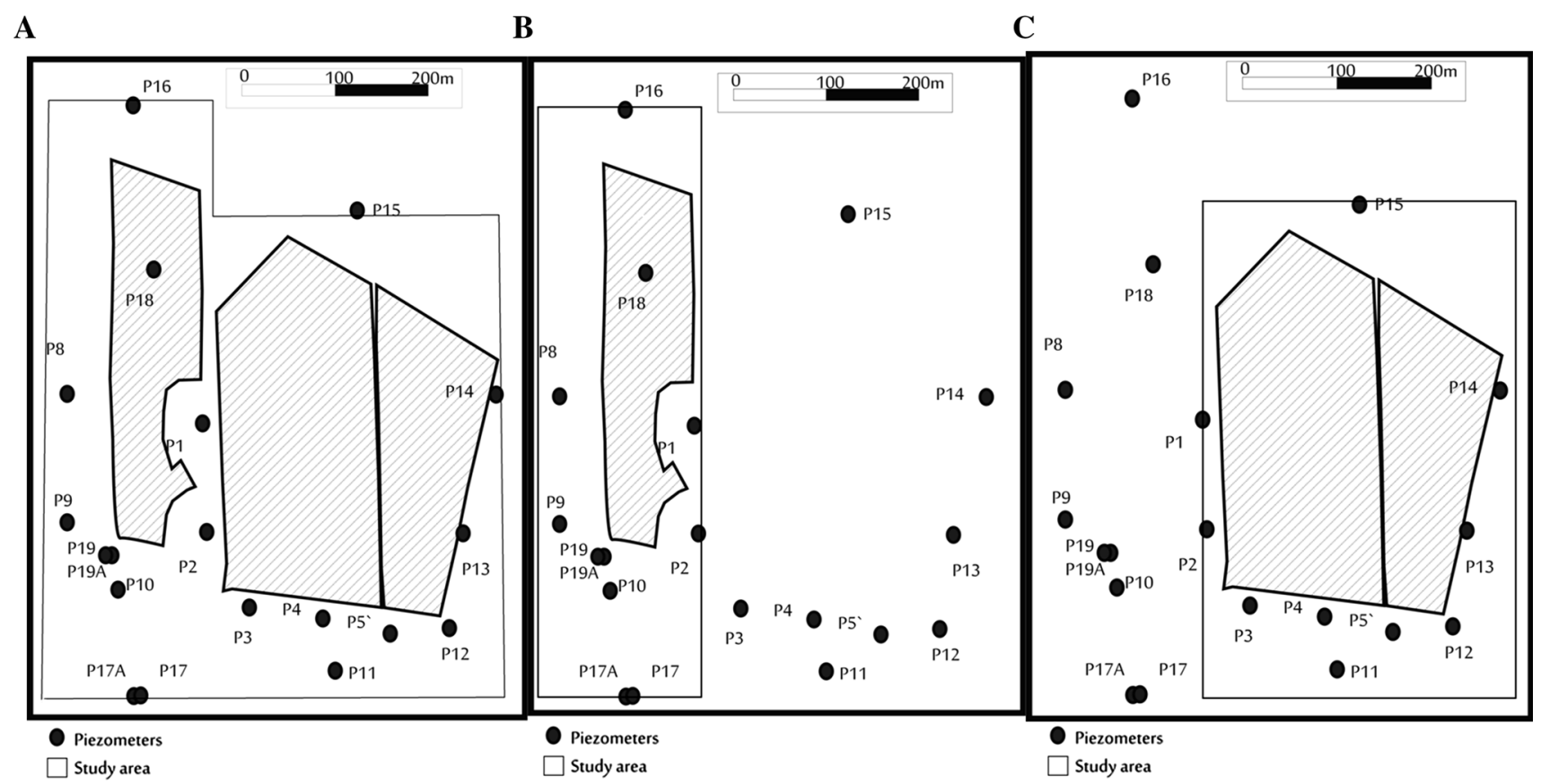

Fig. 6 a-c Extended study areas

Table 5 Values of $R_{\mathrm{u}}$ index for the extended study area of both landfills

\begin{tabular}{llcc}
\hline No. & Piezometers sets & $R_{\mathrm{u}}(\%)$ & $d_{\mathrm{av}}(\mathrm{m})$ \\
\hline 1 & P1, P2, P3, P4, P5‘, P8, P9, P10, P11, P12, P13, P14, P15, P16, P17, P18, P19 & 70.16 & 70.5 \\
2 & P3, P5', P10, P15, P16, P19 & 66.15 & 125.86 \\
3 & P4, P10, P16 & 67.72 & 173.86 \\
\hline
\end{tabular}

Table 6 Values of $R_{\mathrm{u}}$ for the extended study area of the old landfill

\begin{tabular}{llcc}
\hline No. & Piezometers sets & $R_{\mathrm{u}}(\%)$ & $d_{\mathrm{av}}(\mathrm{m})$ \\
\hline 1 & P1, P2, P8, P9, P10, P16, P17, P18, P19 & 68.73 & 71.09 \\
2 & P10, P16, P17, P19 & 56.76 & 130.6 \\
3 & P10, P16, P19 & 63.72 & 134.34 \\
\hline
\end{tabular}

In this context, to determine the optimal test area, additional calculations of the values of the $R_{\mathrm{u}}$ index were performed, for the variant including all piezometers, successively extending the test area in relation to the maximal reach of piezometers (Fig. 7). with the buffer strip with the width from 5 to $200 \mathrm{~m}$. The obtained calculation results are presented in Table 8 . The results show systematic growth of the value of the $R_{\mathrm{u}}$ index from 0 to $95 \mathrm{~m}$, and its decrease proportionally to the growing distance. For the test area with all piezometers located within it and extended in relation to their maximal reach by a 95-m buffer strip, maximal value of the index exceeding the agreed $80 \%(80.41 \%)$ was obtained. In this context, the options with 17 piezometers and the test area described above should be treated as optimal from the point of view of the representativity of the network, determining its homogeneity.

The study area varied from 217,718 to $721,660 \mathrm{~m}^{2}$. Optimal study area is equal to $420,774 \mathrm{~m}^{2}$ and the buffer strip with a width of $95 \mathrm{~m}$.

Representativity index was used previously to determine the homogeneity of the monitoring network for the Lipówka landfill (Dąbrowska et al. 2015) and for the Smolnica landfill (Sarga-Gaczyńska 2007). The studies for the first landfill $\left(18,200,000 \mathrm{~m}^{2}\right)$ were carried out with 8 piezometers in Quaternary and 23 piezometers in Triassic aquifer. In the first case, the index $\mathrm{R}_{\mathrm{u}}$ of $48.2 \%$ and for the second of $49.9 \%$ were calculated. The monitoring network for the Smolnica landfill $\left(1,300,000 \mathrm{~m}^{2}\right)$ consists of 27 points and gives the $\mathrm{R}_{\mathrm{u}}$ index of $72.3 \%$.

\section{Summary}

The representativity index is a measure intended to determine the quality of a monitoring network. However, this index value seems to depend, mainly on the distribution of 
Table 7 Values of $R_{\mathrm{u}}$ for the extended study area of the new landfill

\begin{tabular}{lllr}
\hline No. & Piezometers sets & $R_{\mathrm{u}}(\%)$ & $d_{\mathrm{av}}(\mathrm{m})$ \\
\hline 1 & P1, P2, P3, P4, P5', P11, P12, P13, P14, P15 & 66.79 & 77.58 \\
2 & P3, P4, P5', P11, P12, P15 & 56.35 & 118.71 \\
3 & P3, P5', P15 & 74.75 & 126.58 \\
\hline
\end{tabular}

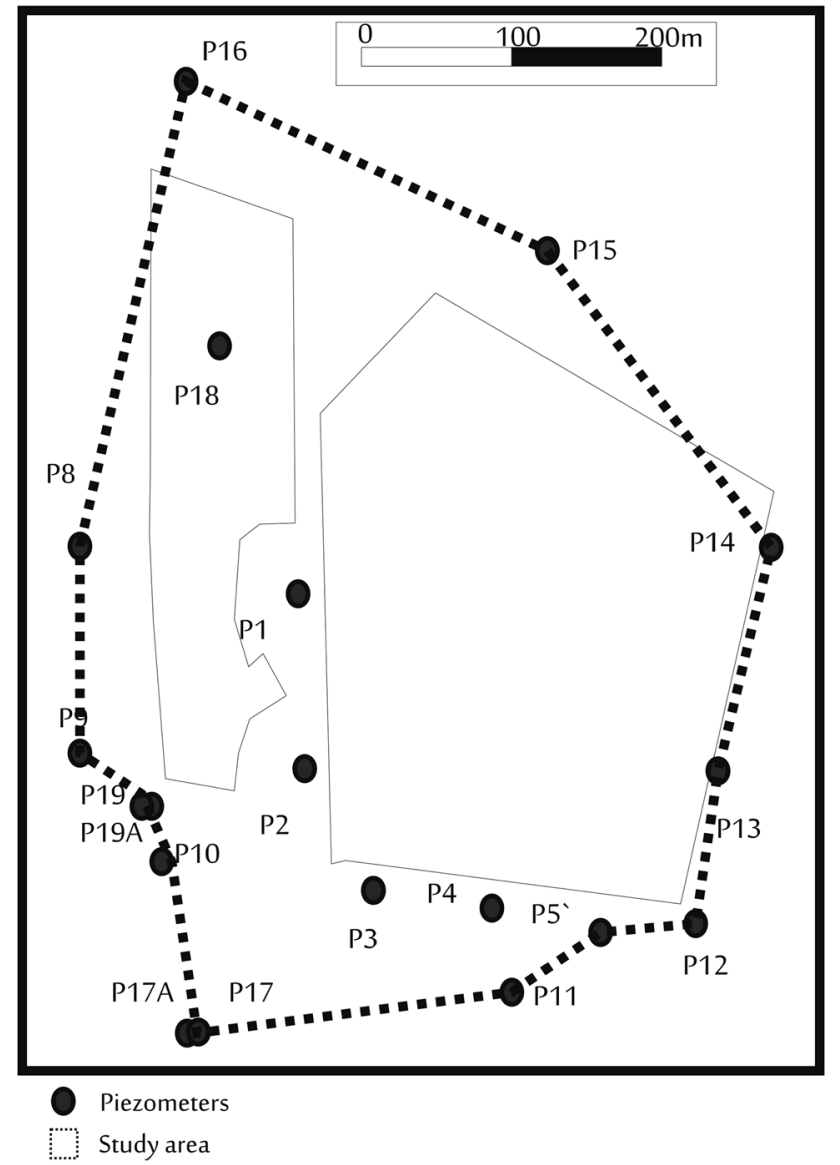

Fig. 7 The study area limited by piezometers network

measurement points and the shape of the study area. The more regular the shape of the test area, the more "representative" the network is. The shape of the test area in the form of a convex polygon allows obtaining greater values of representativity index and for better design of the monitoring network. The results suggest that the representativity index takes into account mostly the homogeneity of the network and in fact, it should be called an index of the network's homogeneity. Another flaw of this indicator is that it suggests that the number of monitoring points is not important, because in most cases fewer points will give a better representativity index of the network. In most cases, the most homogenous network consists of only one monitoring point.

In the case of the system of landfills as the study area, the highest value of the representativity index
Table 8 The index value for the buffer strip

\begin{tabular}{|c|c|c|}
\hline The width (m) & $d_{\mathrm{av}}$ & $R_{\mathrm{u}}$ \\
\hline 0 & 71.17897 & 59.8005 \\
\hline 5 & 70.32855 & 61.7683 \\
\hline 10 & 69.55379 & 63.71515 \\
\hline 15 & 68.87589 & 65.61195 \\
\hline 20 & 68.30579 & 67.44094 \\
\hline 25 & 67.85176 & 69.18085 \\
\hline 30 & 67.51703 & 70.8194 \\
\hline 35 & 67.30485 & 72.34232 \\
\hline 40 & 67.21533 & 73.7392 \\
\hline 45 & 67.24599 & 75.00631 \\
\hline 50 & 67.39605 & 76.13606 \\
\hline 55 & 67.66277 & 77.12728 \\
\hline 60 & 68.04281 & 77.98069 \\
\hline 65 & 68.5333 & 78.69674 \\
\hline 70 & 69.13049 & 79.28113 \\
\hline 75 & 69.83079 & 79.73689 \\
\hline 80 & 70.63077 & 80.0701 \\
\hline 85 & 71.52733 & 80.28848 \\
\hline 90 & 72.51529 & 80.39864 \\
\hline 95 & 73.592 & 80.40873 \\
\hline 100 & 74.75384 & 80.32702 \\
\hline 105 & 75.99657 & 80.16121 \\
\hline 110 & 77.31927 & 79.91949 \\
\hline 115 & 78.71643 & 79.6094 \\
\hline 120 & 80.18614 & 79.23853 \\
\hline 125 & 81.72635 & 78.81344 \\
\hline 130 & 83.33206 & 78.3416 \\
\hline 135 & 85.00316 & 77.82865 \\
\hline 140 & 86.73455 & 77.28078 \\
\hline 145 & 88.52443 & 76.7035 \\
\hline 150 & 90.37198 & 76.10093 \\
\hline 155 & 92.27302 & 75.4782 \\
\hline 160 & 94.22688 & 74.83892 \\
\hline 165 & 96.231 & 74.18671 \\
\hline 170 & 98.28368 & 73.52466 \\
\hline 175 & 100.3833 & 72.85584 \\
\hline 180 & 102.5263 & 72.18332 \\
\hline 185 & 104.7149 & 71.50796 \\
\hline 190 & 106.9426 & 70.83347 \\
\hline 195 & 109.2108 & 70.16065 \\
\hline 200 & 111.519 & 69.49071 \\
\hline
\end{tabular}


$\left(R_{\mathrm{u}}=75.61 \%\right)$ of the monitoring network was received for one point (P1). However, the assessment of the groundwater chemical status using the data from one piezometer, especially in the heterogeneous geochemical conditions within the aquifer, seems to be statistically unjustified and very unreasonable.

The results obtained for different combinations of three points, in accordance with the adequate regulations, indicate that the highest value of the $R_{\mathrm{u}}$ index $(41.23 \%)$ is possible to attain for the new landfill and the worst for the old site $(24.5 \%)$. The result for the old landfill suggests that the minimal monitoring network consisting of three points is far from being representative, from the point of view of $R_{\mathrm{u}}$ index.

Reasonable, in the context of hydrogeological research, configuration for the whole area (P3, P5', P10, P15, P16, $\mathrm{P} 19)$, although provides a determination of the groundwater chemical status or could assist in the making of a contour map, but does not give a satisfactory result $\left(R_{\mathrm{u}}=34.03 \%\right)$.

Calculations were also performed for the test area around the group of landfills, for the monitoring network to be included inside the analyzed area. The calculations were performed for both landfills, for the old landfill and the new landfill. The entire monitoring network was taken into account in the calculations, together with the network optimal from the hydrogeological point of view as well as the minimal network (consistent with the regulations in force).

The difference in the values of the representativity index for subsequent variants (monitoring only for the landfill site and also for the area of landfill with the area limited by the reach of piezometers as the exclusive test area) is astounding. Calculations show that the monitoring network is all the more representative, the more piezometers are located within the study area.

To determine the optimal test area, additional calculations of the values of the $R_{\mathrm{u}}$ index were performed, for the variant including all piezometers, successively extending the test area in relation to the maximal reach of piezometers with the buffer strip. There is quite a big difference in the resulting index value of representativeness for all 17 piezometers when choosing a test area as a dump $(37.19 \%)$ and choosing the study area limited by the network of piezometers, taking into account the buffer strip of a certain width (up to $80 \%$ ).

However, as this measure may be used as a supporting tool to describe the representativity of the monitoring network, the final assessment should be based on a thorough knowledge of the geological structure and hydrogeological conditions.
Acknowledgments Dominika Dąbrowska is a scholarship holder in the project "DoktoRIS—Scholarship program for innovative Silesia" co-financed by the European Union within the European Social Fund.

Open Access This article is distributed under the terms of the Creative Commons Attribution 4.0 International License (http://crea tivecommons.org/licenses/by/4.0/), which permits unrestricted use, distribution, and reproduction in any medium, provided you give appropriate credit to the original author(s) and the source, provide a link to the Creative Commons license, and indicate if changes were made.

\section{References}

Dabrowska D (2012) Variation in the chemical composition of groundwater in the region of the inactive landfill in TychyUrbanowice. M.Sc. thesis, Sosnowiec

Dąbrowska D, Kucharski R, Witkowski JA (2013) The representativity index and representativeness of the monitoring network. Hydrogeoochemia'13. XIV International Scientific Conference, Rubin, Witkowski ed. Wyd. UŚ, Sosnowiec, pp 12-15

Dąbrowska D, Sołtysiak M, Kucharski R (2015) The homogeneity of the groundwater monitoring network in the region of the landfills' system in Strzemieszyce. Pol Geol Rev 63:657-660

Grath J, Scheidleder A, Uhlig S, Weber K, Kralik M, Keimel T, Gruber D (2001) The EU Water Framework Directive: Statistical aspects of the identification of groundwater pollution trends and aggregation of monitoring results. Final report. Austrian Federal Ministry of Agriculture and Forestry, Environment and Water Management

Jousma G, Roelofsen FJ (2004) World-wide inventory on groundwater monitoring. Report nr. GP 2004-1. IGRAC, Utrecht, p 39

Nielsen DM (ed) (2006) Practical handbook of environmental site characterization and ground-water monitoring, 2nd edn. CRC Press, Taylor\&Francis Group, New York, p 1318

Quevauviller P, Fouillac AM, Grath J, Ward R (eds) (2009) Groundwater monitoring. Water quality measurements series. Wiley, New York, p 428

Rentier C, Delloye F, Broyère S, Dassargues A (2006) A framework for an optimized groundwater monitoring network and aggregated indicators. Environ Geol 50(2):194-201

Sarga-Gaczyńska M (2007) Dynamics of generating pollutions on mining waste dumps and their influence on aquatic environment. AGH University of Science and Technology. Ph.D. thesis, Krakow

R Development Core Team (2015) R: a language and environment for statistical computing. R Foundation for Statistical Computing, Vienna, Austria. http://www.R-project.org/

Witczak S, Bronders J, Kania J, Kmiecik E, Różański K, Szczepańska J (2006_ Bridge.Background criteria for the Identification of groundwater thresholds. Research for Policy Support. Deliverable 16: Summary Guidance and Recommendations on Sampling, Measuring and Quality Assurance. Draft report, Krakow

Witkowski JA (2006) Assessing causes of groundwater pollution of Quaternary aquifer in the area of the inactive landfill site in Tychy-Urbanowice. Intergeo Limited Company, Sosnowiec

Witkowski JA (2009) Remarks on groundwater monitoring for communal landfills (in Polish). Biuletyn Państwowego Instytutu Geologicznego. No 436. Hydrogeologia, z. IX/2, Warszawa, pp 535-546 